\title{
Ethnic differences in regional adipose tissue oestrogen receptor gene expression
}

\author{
Julia H Goedecke ${ }^{1,2}$, Mehreen Tootla ${ }^{2}$ and Dheshnie Keswell ${ }^{2}$ \\ ${ }^{1}$ Non-communicable Diseases Research Unit, South African Medical Research Council, Cape Town, South Africa \\ ${ }^{2}$ Division of Exercise Science and Sport Medicine, Department of Human Biology, University of Cape Town, $3^{\text {rd }}$ Floor Sports Science Institute of South \\ Africa, Cape Town, South Africa
}

Correspondence should be addressed to J H Goedecke: julia.goedecke@mrc.ac.za

\begin{abstract}
Studies have shown ethnic differences in body fat distribution, characterised by greater peripheral and less central fat accumulation in black compared to white South African (SA) women. As sex hormones play an important role in body fat distribution, our study aimed to determine whether differences in body fat distribution between black and white SA women were associated with subcutaneous adipose tissue (SAT) expression of oestrogen receptors (ERA and ERB) and aromatase (CYP19A1). Body fat distribution (DXA and CT) and ERA, ERB and CYP19A1 expression in abdominal and gluteal SAT were measured in 26 black and 22 white SA women. Abdominal SAT ERA and ERB did not differ by ethnicity or BMI. Gluteal $E R A$ was higher $(1.08 \pm 0.06$ vs $0.99 \pm 0.05, P<0.001)$ and $E R B$ was lower $(0.99 \pm 0.06$ vs $1.10 \pm 0.07, P<0.001)$ in black vs white SA women. CYP19A1 increased with obesity in all depots $(P<0.001)$. In both black and white SA women, gluteal ERA was associated with lower central fat mass (FM) and greater gynoid FM $(P<0.05)$, while the inverse association was shown for CYP19A1 in all depots $(P<0.01)$. In conclusion, ethnic differences in gluteal $E R A$ expression were associated with differences in body fat distribution previously reported between black and white SA women.
\end{abstract}

Key Words
oestrogen receptor
- aromatase
- adipose tissue
- ethnicity
- gluteal fat
- abdominal fat

\section{Introduction}

Sex hormones are important determinants of regional body fat distribution, as evidenced by gender differences in body fat distribution. Indeed, an increase in oestrogen levels are related to greater gynoid body fat deposition (1), whereas circulating oestrogen deficiency, experienced during the menopausal transition, is associated with an increase in central fat mass (FM), which is reduced with hormone replacement therapy $(2,3)$. Central or upper-body fat accumulation, which comprises both visceral (VAT) and subcutaneous adipose tissue (SAT), is commonly associated with increased cardiometabolic risk, whereas lower-body gluteo-femoral fat accumulation may be protective $(4,5)$.

Within adipose tissue, aromatase (CYP19A1) converts androstenedione to oestrone followed by the conversion to oestrogen (6). CYP19A1 expression was shown to be greater in women with gynoid-type obesity compared to upper-body obesity (7). The effects of oestrogen in adipose tissue are mediated by oestrogen receptors (ERs), ERA and ERB, which are expressed in human adipose tissue $(8,9)$. It has been demonstrated that ERA and ERB have different actions, and ERB may even oppose the actions of ERA (10). Oestrogen receptor knockout (ERKO) mice present with high levels of VAT, insulin resistance and impaired glucose tolerance $(11,12,13)$. Human studies have demonstrated regional differences in adipose tissue $E R A, E R B$ and $C Y P 19 A 1$ expression, which may be altered by sex and age $(9,14,15,16)$. Further, $E R A$ expression is reduced in obese premenopausal women, and expression increases after weight reduction (17). In contrast, (c) 2019 The authors Published by Bioscientifica Ltd
This work is licensed under a Creative Commons Attribution-NonCommercial 4.0 International License. 
$E R B$, but not $E R A$, was significantly higher in adipose tissue of postmenopausal compared to premenopausal women (18).

Studies in the USA and South Africa (SA) have shown that at the same level of BMI, black African women have greater peripheral (gluteo-femoral) FM and abdominal superficial subcutaneous adipose tissue (SSAT), but less VAT than their white counterparts $(19,20,21)$. We hypothesised that the ethnic difference in body fat distribution between black and white SA women may be associated with differences in the SAT gene expression of ERA, ERB and CYP19A1.

Accordingly, in a sample of black and white SA women, we aimed to (i) examine the differences in $E R A, E R B$ and CYP19A1 gene expression in abdominal and gluteal SAT depots and (ii) explore the ethnic-specific associations between gene expression and body fat distribution.

\section{Materials and methods}

The study included 13 normal-weight and 13 obese black and 11 normal-weight and 11 obese white SA women who were recruited as described previously $(22,23)$. In summary, inclusion criteria were (i) age 18-45 years; (ii) no known diseases or taking any medication for metabolic disorders; (iii) not currently pregnant, lactating or postmenopausal and (iv) of self-reported Xhosa ancestry or white SA ancestry (both parents). This study was approved by the Human Research Ethics Committee of the Faculty of Health Sciences of the University of Cape Town. Consent was obtained from each participant after full explanation of the purpose and nature of all procedures used.

Total body FM and android and gynoid regions of interest (ROI) were measured by dual-energy X-ray absorptiometry (DXA, Discovery-W, software version 12.7.3.7, Hologic, Bedford, MA, USA). Android and gynoid ROI were defined automatically using the Hologic software. The android ROI is defined as the area around the waist, with the upper demarcation a 5 th of the distance from neck to waist cut-line and the lower demarcation at the top of the pelvis. The gynoid ROI is twice the height of the android ROI with the upper demarcation below the top of the iliac crest at a distance of 1.5 times the android height. Abdominal VAT, deep subcutaneous adipose tissue (DSAT) and SSAT were measured by CT (Toshiba X-press Helical Scanner, Toshiba). Fasting blood samples were drawn for the analysis of serum oestradiol (E2) concentrations using two-site sandwich immunoassay (Centaur, Siemens). Adipose biopsies were obtained from the DSAT, SSAT and gluteal SAT depots using a mini liposuction method (23). Total RNA was isolated using the QIAGEN RNeasy system (QIAGEN Ltd.), and RT-PCR performed using a StepOnePlus real-time PCR detection system (Applied Biosystems) and TaqMan gene expression assays (Applied Biosystems): ERA (Hs00174860_m1), ERB (Hs00230957_m1/Hs01100353_m1), CYP19A1 (Hs00903413_m1/Hs00240671_m1), 18S (Hs99999901_s1), RPLPO (Hs99999902_m1) and Cyclophilin (PPIA) (Hs04194521_s1). Transcript levels are presented as the ratio of abundance of the gene of interest to the mean of abundance of 18S, PPIA and RPLPO.

Results were analysed using STATA 14 (StataCorp). Normality was tested using Shapiro-Wilk test and presented as mean \pm standard deviation for normally distributed data or median and interquartile range for VAT, which was skewed. Significance was set as $P<0.05$. Differences between ethnic and BMI groups were analysed using two-way ANOVA. Depot-specific differences in gene expression were assessed using repeated-measures mixed models, exploring the interaction with ethnicity and BMI. Pearson's correlation coefficients were used to explore bivariate associations between gene expression and body composition in black and white women separately.

\section{Results}

\section{Participant characteristics}

Participant characteristics have been described in detail previously $(22,23)$ and are presented in Table 1 . White and black SA women did not differ by age, BMI, body fat or DXA-derived regional fat distribution. While abdominal VAT and SSAT did not differ by ethnicity in normal-weight women, obese black SA women had less VAT and more SSAT than their white counterparts. Obese women had less gynoid \%FM (\% of total FM) and greater android \%FM and greater VAT and SAT than normal-weight women. Circulating E2 levels and hormonal contraceptive use (data not shown) did not differ by ethnicity or BMI.

\section{SAT gene expression}

Differences in abdominal DSAT, SSAT and GLUT expression of ERA, ERB and CYP19A1 gene expression between ethnicity and BMI groups are shown in Fig. 1A. Within the abdominal DSAT and SSAT depots, ERA and $E R B$ did not differ by ethnicity or BMI group. However, within the gluteal depot, $E R A$ was higher $(P<0.001)$ and $E R B$ was lower $(P<0.001)$ in black vs white SA women,

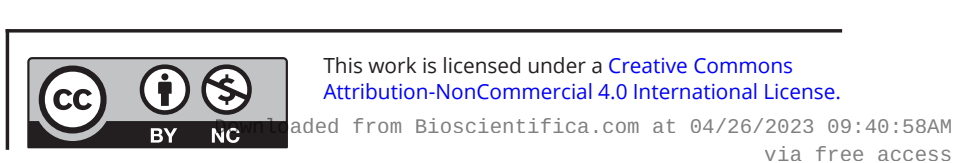


Table 1 Characteristics of normal-weight and obese white and black SA women.

\begin{tabular}{|c|c|c|}
\hline & \multicolumn{2}{|c|}{ Normal weight } \\
\hline & White & Black \\
\hline Age (years) & $25 \pm 4$ & $23 \pm 3$ \\
\hline BMI $\left(\mathrm{kg} / \mathrm{m}^{2}\right)$ & $22.6 \pm 1.5$ & $23.0 \pm 1.6$ \\
\hline Fat $(\mathrm{kg})$ & $19.0 \pm 5.1$ & $17.7 \pm 4.0$ \\
\hline Fat (\%) & $29.2 \pm 7.0$ & $30.9 \pm 5.8$ \\
\hline Android (\%FM) & $6.0 \pm 1.0$ & $5.9 \pm 0.7$ \\
\hline Gynoid (\%FM) & $22.4 \pm 2.9$ & $21.2 \pm 1.8$ \\
\hline VAT $\left(\mathrm{cm}^{2}\right)$ & 49 (41-77) & $57(46-117)$ \\
\hline DSAT $\left(\mathrm{cm}^{2}\right)$ & $79 \pm 39$ & $72 \pm 25$ \\
\hline SSAT $\left(\mathrm{cm}^{2}\right)$ & $100 \pm 34$ & $102 \pm 29$ \\
\hline E2 (pg/mL) & $249 \pm 91$ & $228 \pm 125$ \\
\hline
\end{tabular}

\begin{tabular}{ccc}
\hline \multicolumn{3}{c}{ Obese } \\
\hline White & Black \\
\hline $31 \pm 8^{*}$ & $29 \pm 8^{*}$ \\
$36.5 \pm 6.3^{*}$ & $37.6 \pm 3.7^{\star}$ \\
$45.7 \pm 12.3^{*}$ & & $43.2 \pm 6.7^{*}$ \\
$45.7 \pm 3.9^{*}$ & $47.3 \pm 3.1^{*}$ \\
$8.9 \pm 1.4^{*}$ & $9.0 \pm 1.0^{*}$ \\
$18.6 \pm 2.3^{*}$ & $17.4 \pm 2.1^{*}$ \\
$129(91-20)^{*}$ & $94(68-117)^{*, \#}$ \\
$270 \pm 77^{*}$ & $258 \pm 55^{*}$ \\
$248 \pm 49^{*}$ & $324 \pm 85^{*} \#$ \\
$174 \pm 126$ & $236 \pm 76$
\end{tabular}

Values are expressed as mean \pm standard deviation or median and interquartile range. $P$ values adjusted for age except for age.

${ }^{*} P<0.01$ for difference between obese vs normal-weight black or white women; ${ }^{\#} P<0.05$ for difference between obese black vs white women. BMI, body mass index; DSAT, deep subcutaneous adipose tissue; E2, Oestradiol; FM, fat mass; SSAT, superficial subcutaneous adipose tissue; VAT, visceral adipose tissue.

irrespective of BMI. Moreover, ERA was lower in obese than normal-weight black and white SA women $(P=0.042$ and $P=0.012$, respectively). CYP19A1 was higher in obese than normal-weight black and white SA women in all depots $(P<0.001)$, and within the gluteal depot, CYP19A1 was higher in black than white SA women $(P=0.030)$.

Depot differences in ERA and $E R B$ were not influenced by BMI category ( $P>0.05$ for interaction) and hence normal-weight and obese women were combined to explore depot $x$ ethnicity interactions in gene expression (Fig. 1B). Depot differences in gene expression were altered by ethnicity $(P<0.001$ for ethnicity $\times$ depot). In black SA women, ERA was highest in gluteal SAT, followed by $\operatorname{DSAT}(P=0.048)$ and then SSAT $(P<0.001)$, whereas in white SA women, ERA was greater in DSAT than SSAT $(P=0.011)$ and gluteal SAT $(P=0.025)$. In contrast, in black SA women, $E R B$ was the highest in DSAT, followed by gluteal SAT and then SSAT ( $P<0.01$ for all depots), whereas in White SA women, ERB was the highest in the gluteal depot, followed by the DSAT and SSAT depots $(P<0.01$ for all depots). In both black and white SA women, CYP19A1 was higher in gluteal SAT than SSAT $(P<0.001)$ and DSAT $(P<0.001)$.

\section{Associations between gene expression and body fat and its distribution}

Associations between body fat and its distribution and gluteal ERA and CYP19A1 mRNA levels are shown in Fig. 2A and B, respectively. Gluteal ERA was associated with lower \%FM in white SA women only. In both black and white SA women, gluteal ERA was associated with greater gynoid \%FM, and lower android \%FM, DSAT $(r=-0.45, P=0.032$ and $r=-0.51, P=0.021)$ and SSAT, but not VAT (Fig. 2, Panel A). No associations between gluteal ERB or DSAT and SSAT ERA and ERB and body fat and its distribution were observed for black or white SA women (data not shown). For both black and white SA women, CYP19A1 in all depots was similarly associated with increased total FM and central FM and reduced gynoid \%FM (Fig. 2, Panel B).

\section{Discussion}

We show for the first time ethnic and regional differences in the expression of $E R$ genes between black and white SA women that associated with body fat distribution. The novel and main finding of this study was the markedly elevated ERA and reduced ERB mRNA levels in the gluteal depot of black compared to white SA women, which accounted for the ethnic differences in regional gene expression. These differences were not explained by ethnic differences in E2 levels, which are known to regulate SAT expression of $E R A$ and $E R B$ similarly (9), as E2 levels did not differ between groups. Further, CYP19A1 expression, responsible for local production of E2, was similar between ethnicities, albeit higher in the gluteal depot of black than white SA women.

To our knowledge, Gavin et al. (15) is the only other study that has described ethnic differences in regional protein expression of ERs in a small sample of Caucasian $(n=7)$ and African American $(n=8)$ women. They showed that ERA protein expression was higher in abdominal compared to gluteal depot, and this was largely driven by the Caucasian women, with no differences in African American women. In contrast, ERB expression was higher in the gluteal depot and not different between ethnicities.

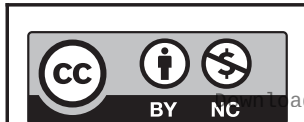




\section{A Ethnicity $\times$ BMI differences}
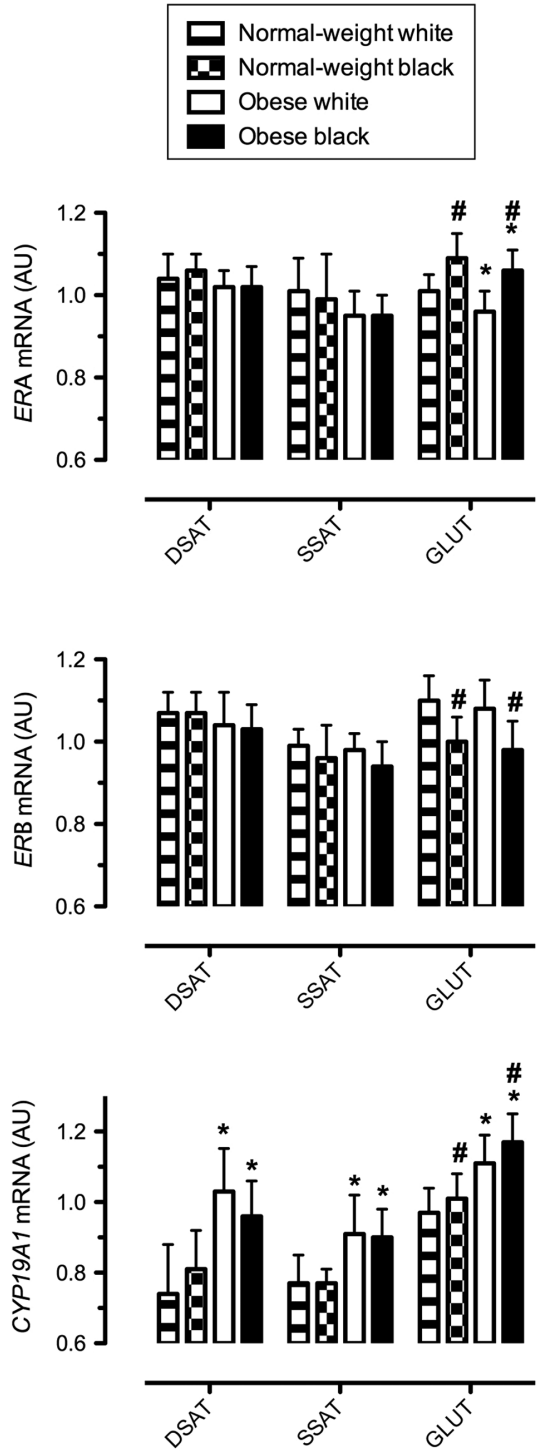

\section{B Ethnicity $\mathbf{x}$ depot differences}

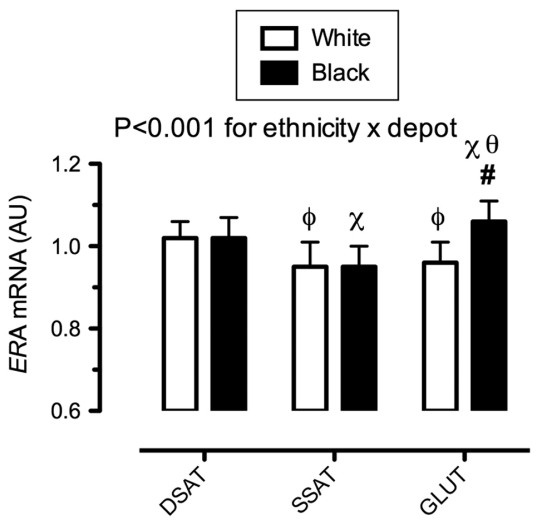

$\mathrm{P}<0.001$ for ethnicity $x$ depot
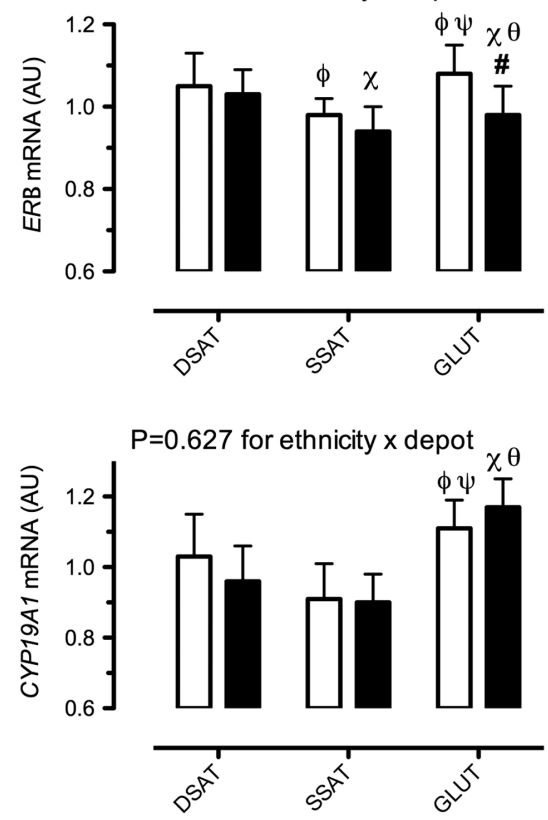

Figure 1

Expression of genes in abdominal deep subcutaneous adipose tissue (DSAT), superficial subcutaneous adipose tissue (SSAT) and gluteal (GLUT) depots of normal-weight and obese, white and black SA women. Panel A: Ethnic and BMI differences in gene expression within each depot. Bars represent mean \pm standard deviation. ${ }^{*} P<0.05$, obese vs normal-weight; ${ }^{\#} P<0.05$, black vs white SA women. Panel B: Depot and ethnic (combining normal-weight and obese groups) differences in gene expression. Bars represent mean \pm standard deviation. $\# P<0.05$, black vs white SA women; $\phi P<0.05$ for differences to DSAT in White SA women; ${ }^{\varphi} P<0.05$ for differences to SSAT in White SA women; $x P<0.05$ for differences to DSAT in black SA women; ${ }^{\theta} P<0.05$ for differences to SSAT in black SA women. CYP19A, aromatase; ERA, oestrogen receptor alpha; ERB, oestrogen receptor beta.
These findings are largely supported by the mRNA results from the white SA women in our study, as well as by other small studies of premenopausal women $(8,9)$. Differences in the findings between the African American and the black SA women may merely be due to a sample size effect ( $n=7$ vs $n=26$, respectively), but may also be confounded by the fact that the African American women had greater centralisation of body fat (android FM) than their white counterparts. Alternatively, differences in genetics, lifestyle (diet and physical activity) and environmental factors may have also played a role.

Notably, in both black and white SA women, greater expression of ERA (and not ERB) in gluteal, and not abdominal SAT, was associated with less central SAT and greater peripheral FM. In contrast to our findings,
Gavin et al. (15) found that ERA protein expression in the abdominal and gluteal regions was not associated with any anthropometric measure of body fat distribution, but lower gluteal ERB protein expression and a higher ERA/ ERB were associated with higher WHR. The findings of Gavin et al. (15) are surprising given that studies of global ERA-knockout (ERKO) mice models have shown that ERKA mice have increased FM, and specifically greater VAT compared to WT mice (11). In contrast, body composition does not differ between $E R B$-knockout (ERKO) mice and WT mice (13), suggesting that ERB has a limited impact on body composition. Although the mechanisms are not entirely clear, Nilsson et al. (24) showed an inverse correlation between abdominal ERA expression and basal lipolysis and adrenoceptor responsiveness in 


\section{A Gluteal ERA mRNA}
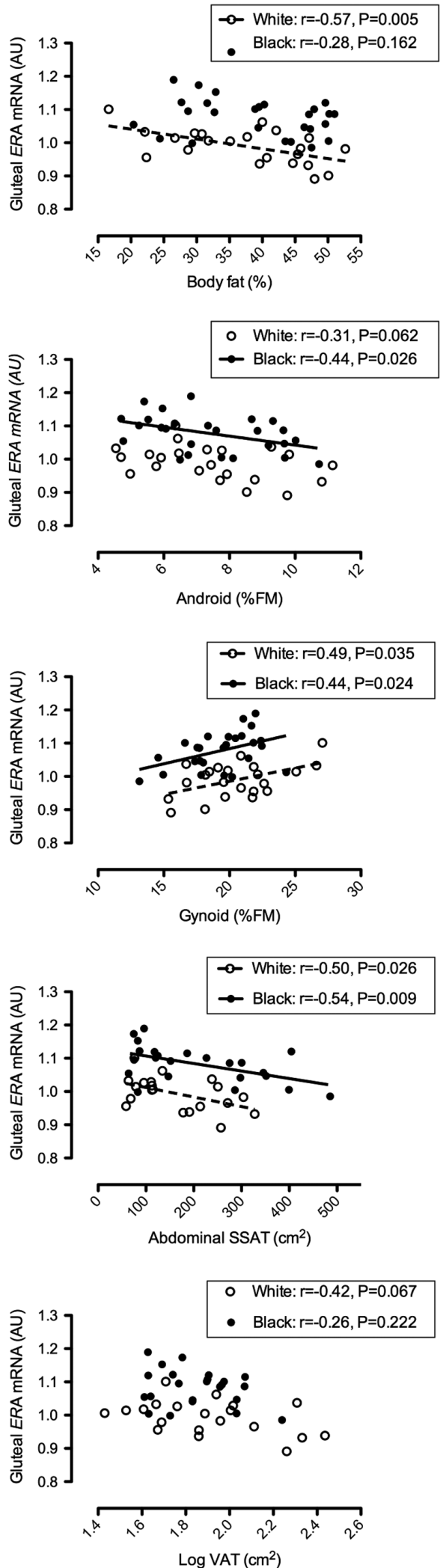

\section{B Gluteal CYP19A1 mRNA}
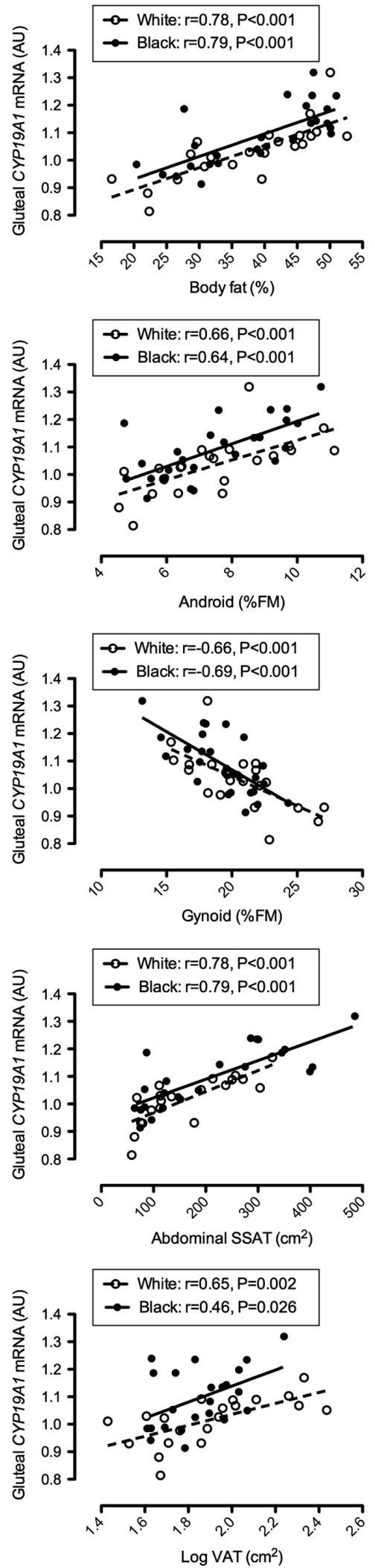

\section{Figure 2}

Associations between gluteal ERA mRNA (A) and CYP19A1 (B) expression and measures of body fat and its distribution in black and white South African women. Values are Pearson correlation coefficients. FM, fat mass, SSAT, superficial subcutaneous adipose tissue; VAT, visceral adipose tissue. 
obese women, possibly explaining the greater peripheral and lower central fat patterning in black compared to white SA women in this study. More recently, adiposespecific $E R A$-knockdown studies in mice have shown that decreased adipose tissue $E R A$ results in larger, fibrotic and inflamed adipocytes (25). We propose that the higher ERA expression in the gluteal depot of black SA women may protect these depots from adipocyte hypertrophy, fibrosis and inflammation, providing a favourable site for storage of excess fatty acids and protecting against central accumulation of fatty acids $(26,27)$.

Studies in humans have shown reduced abdominal SAT ERA gene expression in obese compared to normalweight premenopausal women and increased expression in response to weight loss (17). Although we showed no BMI effects on ERA expression in the abdominal depots, $E R A$ expression was lower in the gluteal depot of obese vs normal-weight white SA women and to a lesser extent, in black SA women. Furthermore, obese women had less gluteal \%FM and more android \%FM than their normalweight counterparts, supporting the associations between $E R A$ expression and body fat distribution observed in black and white SA women.

Due to the cross-sectional nature of this study, it is not known if the associations reported are a cause or a consequence of obesity and the ethnic differences in body fat distribution. Larger studies including the functional assessment of oestrogen action are required to gain a greater understanding of these observations. Another limitation of the study is the absence of protein expression. However, it has been consistently shown that ERA and ERB protein expression corresponds to the mRNA levels, showing similar between-depot and gender differences $(8,9)$.

In conclusion, black SA women had greater gluteal ERA expression than white SA women. This study provides preliminary evidence that ethnic differences in gluteal ERA gene expression may explain the differences in body fat distribution previously reported between black and white SA women. Future studies including a larger, more representative sample of black and white SA women and incorporating more mechanistic aspects of oestrogen action are required to verify these findings.

\section{Declaration of interest}

The authors declare that there is no conflict of interest that could be perceived as prejudicing the impartiality of the research reported.

\section{Funding}

This work was supported by the South African Medical Research Council, the University of Cape Town, the International Atomic Energy Agency and the National Research Foundation of South Africa.

\section{Author contribution statement}

$\mathrm{J} H \mathrm{G}$ and $\mathrm{D} \mathrm{K}$ were involved in the study design, data collection and analysis, writing and approving the final manuscript for submission. M T was involved in data collection, analysis and writing of the manuscript.

\section{Acknowledgements}

The authors would like to acknowledge the excellent clinical and technical assistance from Phillip Hayes, Hendriena Victor and Nandipha Sinyanya.

\section{References}

1 Yeung EH, Zhang C, Albert PS, Mumford SL, Ye A, Perkins NJ, Wactawski-Wende J \& Schisterman EF. Adiposity and sex hormones across the menstrual cycle: the BioCycle Study. International Journal of Obesity 201237 237-243. (https://doi.org/10.1038/ijo.2012.9)

2 Hevener AL, Clegg DJ \& Mauvais-Jarvis F. Impaired estrogen receptor action in the pathogenesis of the metabolic syndrome. Molecular and Cellular Endocrinology 2015418 (Pt 3) 306-321. (https://doi. org/10.1016/j.mce.2015.05.020)

3 Gambacciani M, Ciaponi M, Cappagli B, Piaggesi L, De Simone L, Orlandi R \& Genazzani AR. Body weight, body fat distribution, and hormonal replacement therapy in early postmenopausal women. Journal of Clinical Endocrinology and Metabolism 199782 414-417. (https://doi.org/10.1210/jcem.82.2.3735)

4 Blüher M. Importance of estrogen receptors in adipose tissue function. Molecular Metabolism 20132 130-132. (https://doi. org/10.1016/j.molmet.2013.07.001)

5 Seidell JC, Perusse L, Després JP \& Bouchard C. Waist and hip circumferences have independent and opposite effects on cardiovascular disease risk factors: the Quebec Family Study. American Journal of Clinical Nutrition 200174 315-321. (https://doi. org/10.1093/ajcn/74.3.315)

6 Simpson ER, Mahendroo MS, Means GD, Kilgore MW, Hinshelwood MM, Graham-Lorence S, Amarneh B, Ito Y, Fisher CR \& Michael MD. Aromatase cytochrome P450, the enzyme responsible for estrogen biosynthesis. Endocrine Reviews 199415 342-355. (https://doi. org/10.1210/edrv-15-3-342)

7 Kirschner MA, Samojlik E, Drejka M, Szmal E, Schneider G \& Ertel N. Androgen-estrogen metabolism in women with upper body versus lower body obesity. Journal of Clinical Endocrinology and Metabolism 199070 473-479. (https://doi.org/10.1210/jcem-70-2-473)

8 Pedersen SB, Bruun JM, Hube F, Kristensen K, Hauner H \& Richelsen B. Demonstration of estrogen receptor subtypes alpha and beta in human adipose tissue: influences of adipose cell differentiation and fat depot localization. Molecular and Cellular Endocrinology 2001182 27-37. (https://doi.org/10.1016/S0303-7207(01)00557-3)

9 Dieudonne MN. Evidence for functional estrogen receptors and in human adipose cells: regional specificities and regulation by estrogens. AJP: Cell Physiology 2004286 655C-661C. (https://doi. org/10.1152/ajpcell.00321.2003)

10 Hall JM. The estrogen receptor-alpha isoform (ERalpha) of the human estrogen receptor modulates ER transcriptional activity and is a key regulator of the cellular response to estrogens and

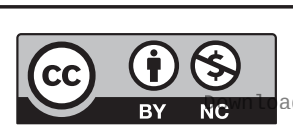

This work is licensed under a Creative Commons Attribution-NonCommercial 4.0 International License. ded from Bioscientifica.com at 04/26/2023 09:40:58AM 
antiestrogens. Endocrinology 1999140 5566-5578. (https://doi. org/10.1210/endo.140.12.7179)

11 Heine PA, Taylor JA, Iwamoto GA, Lubahn DB \& Cooke PS. Increased adipose tissue in male and female estrogen receptor-alpha knockout mice. PNAS 200097 12729-12734. (https://doi.org/10.1073/ pnas.97.23.12729)

12 Bryzgalova G, Gao H, Ahrén B, Zierath JR, Galuska D, Steiler TL, Dahlman-Wright K, Nilsson S, Gustafsson JA, Efendic S, et al. Evidence that oestrogen receptor- $\alpha$ plays an important role in the regulation of glucose homeostasis in mice: insulin sensitivity in the liver. Diabetologia 200649 588-597. (https://doi.org/10.1007/s00125-005-0105-3)

13 Ohlsson C, Hellberg N, Parini P, Vidal O, Bohlooly M, Rudling M, Lindberg MK, Warner M, Angelin B \& Gustafsson J-Å. Obesity and disturbed lipoprotein profile in estrogen receptor- $\alpha$-deficient male mice. Biochemical and Biophysical Research Communications 2000278 640-645. (https://doi.org/10.1006/bbrc.2000.3827)

14 Pedersen SB, Hansen PS, Lund S, Andersen PH, Odgaard A \& Richelsen B. Identification of oestrogen receptors and oestrogen receptor mRNA in human adipose tissue. European Journal of Clinical Investigation 199626 262-269. (https://doi.org/10.1046/j.1365-2362.1996.145278.x)

15 Gavin KM, Cooper EE \& Hickner RC. Estrogen receptor protein content is different in abdominal than gluteal subcutaneous adipose tissue of overweight-to-obese premenopausal women. Metabolism Clinical and Experimental 201362 1180-1188. (https://doi. org/10.1016/j.metabol.2013.02.010)

16 Bulun S \& Simpson E. Competitive reverse transcription-polymerase chain reaction analysis indicates that levels of aromatase cytochrome P450 transcripts in adipose tissue of buttocks, thighs, and abdomen of women increase with advancing age. Journal of Clinical Endocrinology and Metabolism 199478 428. (https://doi.org/10.1210/ jcem.78.2.8106632)

17 Nilsson M, Dahlman I, Ryden M, Nordström EA, Gustafsson JA, Arner P \& Dahlman-Wright K. Oestrogen receptor $\alpha$ gene expression levels are reduced in obese compared to normal weight females. International Journal of Obesity 200731 900-907. (https://doi. org/10.1038/sj.ijo.0803528)

18 McInnes KJ, Andersson TC, Šimonytė K, Söderström I, Mattsson C, Seckl JR \& Olsson T. Association of 11ß-hydroxysteroid dehydrogenase type I expression and activity with estrogen receptor $\beta$ in adipose tissue from postmenopausal women. Menopause 201219 1347-1352. (https://doi.org/10.1097/gme.0b013e318258aad7)
19 Goedecke JH, Dave JA, Faulenbach MV, Utzschneider KM, Lambert EV, West S, Collins M, Olsson T, Walker BR, Seckl JR, et al. Insulin response in relation to insulin sensitivity: an appropriate beta-cell response in black South African women. Diabetes Care 200932 860-865. (https://doi.org/10.2337/dc08-2048)

20 Lovejoy JC, la Bretonne de JA \& Tulley R. Abdominal fat distribution and metabolic risk factors: effects of race. Metabolism Clinical and Experimental 199645 1119-1124. (https://doi.org/10.1016/S00260495(96)90011-6)

21 Rush EC, Goedecke JH, Jennings C, Micklesfield L, Dugas L, Lambert EV \& Plank LD. BMI, fat and muscle differences in urban women of five ethnicities from two countries. International Journal of Obesity 200731 1232-1239. (https://doi.org/10.1038/sj.ijo.0803576)

22 Goedecke JH, Levitt NS, Lambert EV, Utzschneider KM, Faulenbach MV, Dave JA, West S, Victor H, Evans J, Olsson T, et al. Differential effects of abdominal adipose tissue distribution on insulin sensitivity in black and white South African women. Obesity 200917 15061512. (https://doi.org/10.1038/oby.2009.73)

23 Evans J, Goedecke JH, Söderström I, Burén J, Alvehus M, Blomquist C, Jonsson F, Hayes PM, Adams K, Dave JA, et al. Depot- and ethnicspecific differences in the relationship between adipose tissue inflammation and insulin sensitivity. Clinical Endocrinology 201074 51-59. (https://doi.org/10.1111/j.1365-2265.2010.03883.x)

24 Nilsson M, Dahlman I, Jiao H, Gustafsson J-Å, Arner P \& DahlmanWright K. Impact of estrogen receptor gene polymorphisms and mRNA levels on obesity and lipolysis - a cohort study. BMC Medical Genetics 20078 325. (https://doi.org/10.1186/1471-2350-8-73)

25 Davis KE, Neinast MD, Sun K, Skiles WM, Bills JD, Zehr JA, Zeve D, Hahner LD, Cox DW, Gent LM, et al. The sexually dimorphic role of adipose and adipocyte estrogen receptors in modulating adipose tissue expansion, inflammation, and fibrosis. Molecular Metabolism 20132 227-242. (https://doi.org/10.1016/j. molmet.2013.05.006)

26 Virtue S \& Vidal-Puig A. Adipose tissue expandability, lipotoxicity and the Metabolic Syndrome - an allostatic perspective. Biochimica et Biophysica Acta 20101801 338-349. (https://doi.org/10.1016/j. bbalip.2009.12.006)

27 Pellegrinelli V, Carobbio S \& Vidal-Puig A. Adipose tissue plasticity: how fat depots respond differently to pathophysiological cues. Diabetologia 201659 1075-1088. (https://doi.org/10.1007/s00125016-3933-4)

Received in final form 14 December 2018

Accepted 18 December 2018

Accepted Preprint published online 18 December 2018 https://ec.bioscientifica.com https://doi.org/10.1530/EC-18-0531 (c) 2019 The authors Published by Bioscientifica Ltd

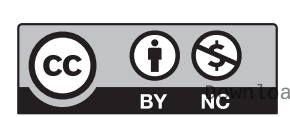

This work is licensed under a Creative Commons Attribution-NonCommercial 4.0 International License. ded from Bioscientifica.com at 04/26/2023 09:40:58AM 